International Journal of Linguistics, Literature and Culture
Available online at https://sloap.org/journals/index.php/ijllc/
Vol. 6, No. 2, March 2020, pages: 59-66
$\begin{aligned} & \text { ISSN: 2455-8028 } \\ & \text { https://doi.org/10.21744/ijllc.v6n2.875 }\end{aligned}$

\title{
The Cognitive Process and Influence in Learning
}

\author{
Enrique Byron Ayón Parrales a \\ Josefa Katiuska Toala Palma ${ }^{b}$ \\ Romina Adelina Quevedo Álava ${ }^{c}$ \\ Marcos Fernando Pazmiño Campuzano ${ }^{d}$
}

Article history:

Submitted: 27 January 2019

Revised: 18 February 2020

Accepted: 09 March 2020

\section{Keywords:}

cognitive processes; executive functions; learning; school performance; teaching strategies;

\section{Corresponding author:}

Enrique Byron Ayón Parrales,

Pontificia Universidad Católica del Ecuador, sede Manabí, Portoviejo, Ecuador.

Email address: enryayon@hotmail.com

\begin{abstract}
Learning is linked to the interactions of human brain functions. Every teacher or person who is linked to education is faced with the need and obligation to know how the human brain works and at the same time stimulate it with techniques and strategies that facilitate the assimilation of teaching. Cognitive processes play an important role in education, this help to interact preconceptions and knowledge with their natural and social environment, including processes in which it involves learning with which we acquire knowledge daily and routinely, whether it gives implicitly or explicitly, it helps to solve diverse situations, establishing logical and adequate connections with the help of reasoning because it conducts a behavioral and cognitive process of concentration that keeps us attentive.
\end{abstract}

International journal of linguistics, literature and culture (C) 2020. This is an open access article under the CC BY-NC-ND license (https://creativecommons.org/licenses/by-nc-nd/4.0/).

${ }^{a}$ Pontificia Universidad Católica del Ecuador, sede Manabí, Portoviejo, Ecuador

${ }^{\mathrm{b}}$ Pontificia Universidad Católica del Ecuador, sede Manabí, Portoviejo, Ecuador

${ }^{\text {c }}$ Pontificia Universidad Católica del Ecuador, sede Manabí, Portoviejo, Ecuador

${ }^{\mathrm{d}}$ Pontificia Universidad Católica del Ecuador, sede Manabí, Portoviejo, Ecuador 


\section{Introduction}

Nowadays, new generations face greater demands for learning, such as mastering each process, understanding the modern world and take advantage of the new technologies. All human beings are constantly learning and it is given day by day. Daily learning can be given implicitly and explicitly, "students can be taught cognitive strategies to learn to think, learn to learn and learn to be, and thus prevent their difficulties in learning in the classroom and life." (Haro \& Alejandra, 2010).

Some authors state "the need to learn refers to the teaching of strategies that have been formulated in different theories on how to carry it out, either as a curricular area, well integrated into the different subjects or as extracurricular content" (Jabaloyes Sáez, 2016). To face the challenges that arise in daily life as teachers, there is a need to know and use strategies that help facilitate the teaching-learning process. "Teaching cannot be understood except to learning; and this reality relates not only to the processes linked to teaching but also to those linked to learning" (Menese Benites, 2007). So, learning is linked to cognitive processes, these processes must be approached appropriately to obtain optimal results, you have to have aptitude and empathy to get fully involved in student learning.

The educational institutions play an important role in the school environment, from the levels of concretion, especially in the institutional one, internal policies must be created that help students find their potential to achieve teaching in an optimal and directed way, each student It is a productive entity eager to learn, but with different ways of doing it. "Learning styles are constructs that we all have, which affect the way of learning and teaching, so it is necessary to take them into account when planning, executing and evaluating classes" (Castro \& Guzman, 2005). When carrying out the administrative work of the teaching-learning process, the diversity of styles and ways of learning of each individual must be taken into account and analyzed, with this the quality of education is significantly improved. The study is considered novel since no bibliographies have been found on the conduct of research in this regard in the province of Manabí and especially in the Educational Unit "Eleodoro González Cañarte", hence its importance and scientific impact, as it may constitute a point of heading for future research on the subject addressed. Based on the foregoing, the article aims to determine the influence that cognitive processes have on learning (Gumora \& Arsenio, 2002; Meyer, 1997; Barry et al., 2002).

\section{Materials and Methods}

Due to the investigative nature of the work, based on cognitive processes and their influence on learning, the inductive-deductive method was used, which allowed to carry out the research that had a non-experimental qualitative approach without the use of quantitative variables. A bibliographic review was carried out that included the study of articles, books, manuals, institutional documents, among others, being able to analyze the information related to the influence of cognitive processes in learning, which served for the development of research.

\section{Results and Discussions}

\subsection{Cognitive processes}

\section{The focus of cognitive processes}

When reference is made to teaching, the processes involved in learning must be made directly, they help the process in parallel with knowledge and the environment. Quintero \& Melo (2012), Affirm "In every educational process there are differences between students; While some easily adapt to educational programs and respond satisfactorily, others present great difficulties in assimilating the knowledge provided by academic plans "(p.90). The diversity of each student influences the educational processes, these differences play an important role in the teaching-learning process, all this is linked to the adaptation that each person manages to have, who better adapts, better school performance.

For a student to achieve optimal results in the teaching-learning process, they must relate and adapt to the environment, in most cases the socioeconomic level and folklore of people, influence these educational processes. Pérez Pulido (2016), states that "students must possess certain objectified and economic cultural capitals, which they 
generally obtain with the help of their parents... when the student comes from low-income contexts, all family members establish a common strategy to support it" (p.259). The socio-economic status of families influences the learning and performance of students, there are homes where only the firstborn studies, he receives support from parents because they are observed as a hope to improve the quality of life (Fogarty \& Stern, 1989; Pressing, 1984).

\subsection{Learning}

\section{Learning analysis}

Learning is based on how to properly use the executive functions of the brain, the teacher who wants to reach his students must know the functions of the brain and how to stimulate them. Puebla Wuth (2009), argues that "there is a consensus in neurosciences referred to the term Executive Functions (FE), thus calling a set of neural functions that allow metacognition to be related as an intelligent process, with brain activity in humans" ( p.2). For the diversity of students to learn and assimilate the teaching-learning process, the teacher must analyze and stimulate executive functions using metacognitive processes and with this, students with the help of their intellectual abilities can adequately solve any difficulty that may arise. I present it to you.

The human being daily meets the need to experiment and learn to meet their needs and the advancement of technology. He maintains that "lifelong learning is considered one of the main objectives of supranational organizations and the various national educational administrations for several decades" (Belando-Montoro, 2017). Learning is considered as one of the main objectives of living beings and even more of the state portfolios, which are linked to education, for decades the national government, through the Ministry of Education has been concerned with the level and quality of education by creating policies that govern teacher performance pedagogically and administratively (Billett, 1996; Lewalter, 2003; Kirschner, 2002).

Teachers to achieve the training and educational work need to have knowledge in techniques related to learning and cognitive processes and thus perform their activity properly. It means that "For every teacher, knowledge of the different stages of learning as a process is of transcendental importance. This makes it easier for teachers to achieve optimal learning by their students" (Yanes, 2016). Having knowledge related to the cognitive functioning of the brain such as receiving, selecting, storing, transforming, preparing and retrieving information, and of the stages of learning such as conscious and unconscious competences help us predominantly to achieve the expected objectives in the learning of the students.

\subsection{Academic}

The performance of the students is a constant concern on the part of the authorities and of the teachers, day by day it is evident in the reports of partial and quimestres grades are not the best, this performance is linked to the didactic and technical activities used by the teacher. Lamas (2015), Affirms that "School performance is a problem that deeply concerns students, parents, teachers, and authorities (...). The complexity of academic performance starts with its conceptualization. It is sometimes called school aptitude, academic performance or school performance" (p.315). For the educational community (students, parents, teachers, authorities) school performance is a priority and a problem that impatiently worries. Cognitive assimilation and school performance depend on the biological conditions and the student's environment.

The students' academic performance is the positive or negative result of family relationships, customs, socioeconomic status, physical and mental state. López Mero (2015), states:

The causes of poor academic performance are varied, which can be stated: family disintegration, parenting styles, working parents, parents' disinterest, addictions, favorite children, unwanted children, for Quote some. These causes may be associated with pedagogical and personal variables of the student (p.3). At the time of analyzing the report cards and finding ourselves with low academic performance, it was evidenced that the majority of students come from homes with parents who for work reasons are not all the time with children and dysfunctional homes, another cause is the factor emotional, causing personality alterations affecting academic performance.

All students are labeled bad or good about the results of school performance, it is believed that all have the same cognitive conditions, which is why, in certain cases, they are discriminated against and even excluded. In academic life, skill and effort are not synonyms; the effort does not guarantee success, and the skill begins to gain greater importance. This is due to a certain cognitive capacity that allows the student to make a mental elaboration of the causal implications of managing self-perceptions of ability and effort (Edel Navarro, 2003). Each human being is

Parrales, E. B. A., Palma, J. K. T., Álava, R. A. Q., \& Campuzano, M. F. P. (2020). The cognitive process and influence in learning. International Journal of Linguistics, Literature and Culture, 6(2), 59-66. https://doi.org/10.21744/ijllc.v6n2.875 
different from another, not all of us think in the same way or act equally, usually, teachers tend to confuse effort with skill, just because a student tries hard, does not mean that he is going to have a better performance in their school life, on the other hand, skilled students tend to obtain better results in school development due to the skills that they have by nature, this being the strength of skilled students (Karma et al., 2019; Teel et al., 1998; Tulbure, 2012). Figure 1. Schematic representation Cognitive Processes and their Influence on Learning by several authors.

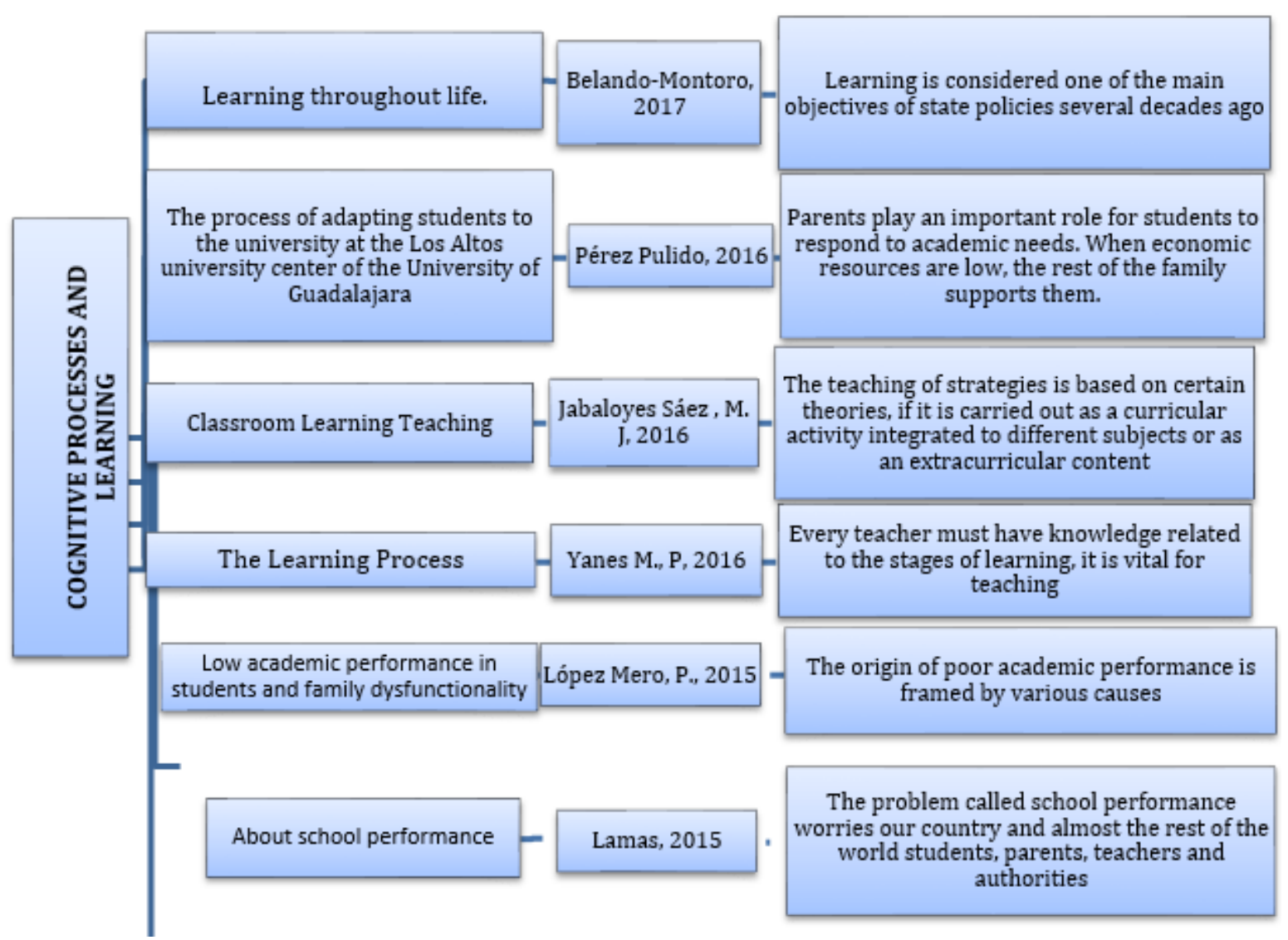

Figure 1. Schematic representation Cognitive Processes

In Figure 1, the main authors cited in this research establish the positive value of learning and teaching as a continuous process of the human being, composed of four elements teacher, student, content and environmental variables, taking into consideration that learning and teaching are two different actions but they are supplementary in the educational field to consolidate knowledge in the students and create an interpretation of the world around us. 


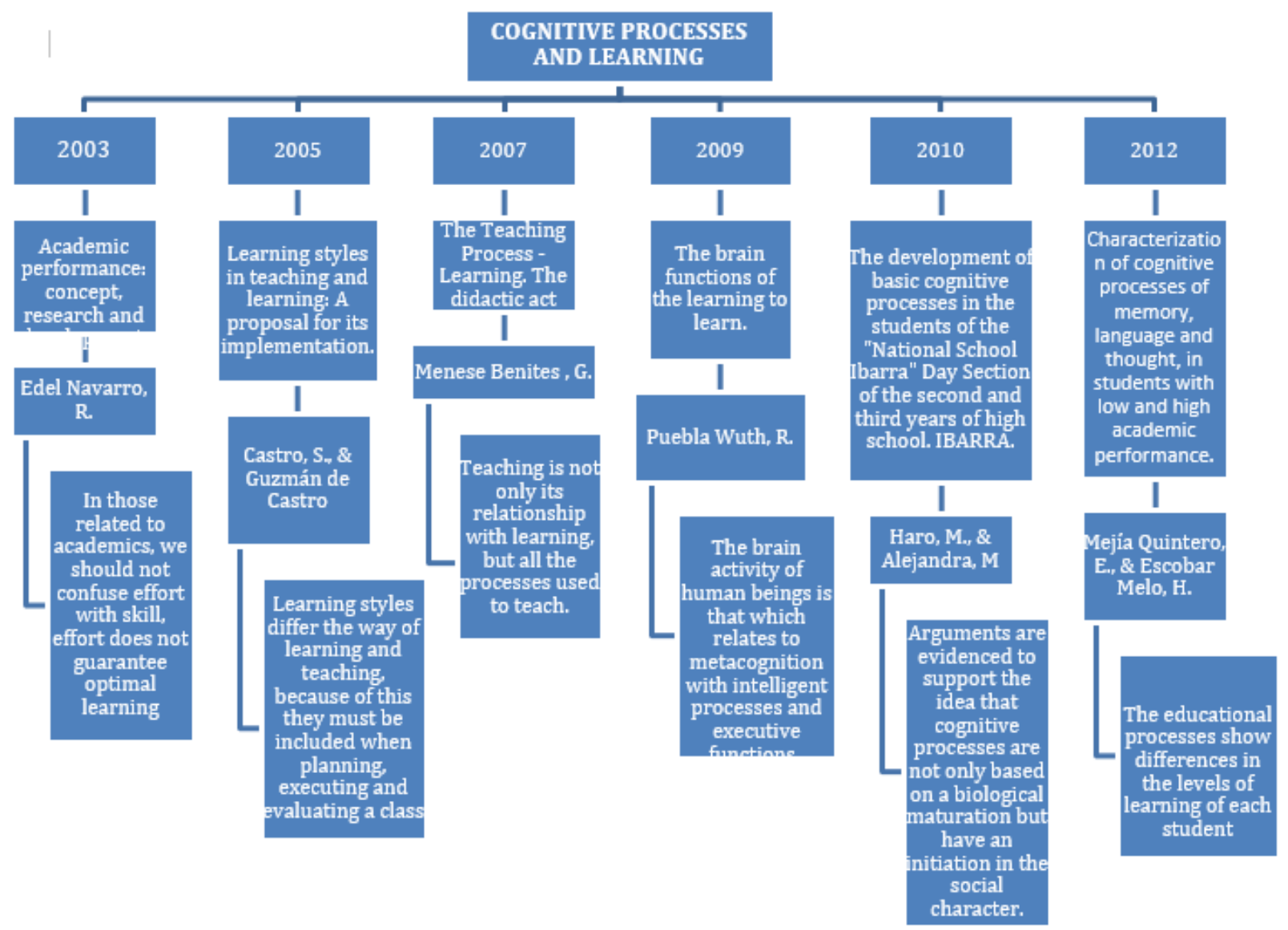

Figure 2. Criteria of the different authors from 2003 to 2012

The main authors mentioned in this research paper describe that the cognitive process refers to all the internal organizations of the mind, how people acquire knowledge, and the understanding of the learning according to the chronological age of the students. By becoming itself, learning is an important dialectical process since knowledge is appropriated through it and helps the individual develop skills to learn, progress, grow intellectually and recognize their style of education.

\section{Conclusion}

After completing the corresponding research and using the methods mentioned above, it is indicated that the use of cognitive processes in the educational field helps importantly in the teaching-learning process. In addition to the study of the human brain through neurosciences they facilitate learning because, thanks to these diagnoses, we analyze all brain functions, especially executive functions, remember that not everyone acts or thinks the same as another, there is A diversity of thoughts and ways of learning, we can carry out activities differentiated or adapted to each educational need. Consequently, in the administrative function of education, teachers must include strategies, techniques, and skills that involve cognitive processes to achieve excellent teaching performance and thus achieve the objectives proposed in the planning.

Parrales, E. B. A., Palma, J. K. T., Álava, R. A. Q., \& Campuzano, M. F. P. (2020). The cognitive process and influence in learning. International Journal of Linguistics, Literature and Culture, 6(2), 59-66. 
Conflict of interest statement

The authors declared that they have no competing interests.

Statement of authorship

The authors have a responsibility for the conception and design of the study. The authors have approved the final article.

Acknowledgments

We are grateful to two anonymous reviewers for their valuable comments on the earlier version of this paper. 


\section{References}

Barry, T. D., Lyman, R. D., \& Klinger, L. G. (2002). Academic underachievement and attention-deficit/hyperactivity disorder: The negative impact of symptom severity on school performance. Journal of school psychology, 40(3), 259-283. https://doi.org/10.1016/S0022-4405(02)00100-0

Belando - Montoro, MR (2017). Learning throughout life. Concept and components. Ibero-American Journal of Education, 75, 219-234.

Billett, S. (1996). Situated learning: Bridging sociocultural and cognitive theorising. Learning and instruction, 6(3), 263-280. https://doi.org/10.1016/0959-4752(96)00006-0

Castro, S., \& Guzmán, B. (2005). Learning styles in teaching and learning: a proposal for its implementation. Research journal, (58), 4.

Fogarty, C., \& Stern, J. A. (1989). Eye movements and blinks: their relationship to higher cognitive processes. International Journal of Psychophysiology, 8(1), 35-42. https://doi.org/10.1016/0167-8760(89)900172

Gumora, G., \& Arsenio, W. F. (2002). Emotionality, emotion regulation, and school performance in middle school children. Journal of school psychology, 40(5), 395-413. https://doi.org/10.1016/S0022-4405(02)00108-5

Haro, M., \& Alejandra, M. (2010). The development of basic cognitive processes in the students of the "National School Ibarra" Day Section of the second and third years of high school. IBARRA.

Jabaloyes Sáez, M.J. (2016). Teaching learning in the classroom.

Karma, I. G. M., Darma, I. K., \& Santiana, I. M. A. (2019). Teaching strategies and technology integration in developing blended learning of applied mathematics subject. International Research Journal of Engineering, IT \& Scientific Research, 5(5), 16-25. https://doi.org/10.21744/irjeis.v5n5.726

Kirschner, P. A. (2002). Cognitive load theory: Implications of cognitive load theory on the design of learning. https://doi.org/10.1016/S0959-4752(01)00014-7

Lamas, H. A. (2015). School Performance. Journal of Educational Psychology-Propositos y Representaciones, 3(1), 351-385.

Lewalter, D. (2003). Cognitive strategies for learning from static and dynamic visuals. Learning and Instruction, 13(2), 177-189. https://doi.org/10.1016/S0959-4752(02)00019-1

López Mero, P. (2015). Low academic performance in students and family dysfunctionality Medisan, $19(9), 3$.

Menese Benites, G. (2007) The Teaching - Learning Process: The didactic act. Tarragona

Meyer, R. H. (1997). Value-added indicators of school performance: A primer. Economics of Education Review, 16(3), 283-301. https://doi.org/10.1016/S0272-7757(96)00081-7

Navarro, R. E. (2003). The Academic Performance: Concept, research and development. REICE. Iberoameri-can Virtual Journal on Quality, Efficacy and Change in Education, July-December, year, 1(002).

Pérez-Pulido, I. (2016). The process of adaptation of the students to the university in the University Center of Los Altos of the University of Guadalajara.

Pressing, J. (1984). Cognitive processes in improvisation. In Advances in Psychology (Vol. 19, pp. 345-363). NorthHolland. https://doi.org/10.1016/S0166-4115(08)62358-4

Puebla Wuth, R. (2009). The brain functions of the learning to learn. Revista Iberoamericana de Educación., $3(50), 2$.

Quintero, EM, \& Melo, HE (2012). Characterization of cognitive processes of memory, language and thought, in students with low and high academic performance. Diversitas: Perspectivas en Psicología, 8 (1), 123-138.

Teel, K. M., Debruin-Parecki, A., \& Covington, M. V. (1998). Teaching strategies that honor and motivate inner-city African-American students: A school/university collaboration. Teaching and Teacher Education, 14(5), 479-495. https://doi.org/10.1016/S0742-051X(98)00001-8

Tulbure, C. (2012). Learning styles, teaching strategies and academic achievement in higher education: A crosssectional investigation. Procedia-Social and Behavioral Sciences, 33, 398-402. https://doi.org/10.1016/j.sbspro.2012.01.151

Yanes M., P. (2016). The Learning Process San Gregorio, 9(11), 72.

Parrales, E. B. A., Palma, J. K. T., Álava, R. A. Q., \& Campuzano, M. F. P. (2020). The cognitive process and influence in learning. International Journal of Linguistics, Literature and Culture, 6(2), 59-66. https://doi.org/10.21744/ijllc.v6n2.875 


\section{Biography of Authors}

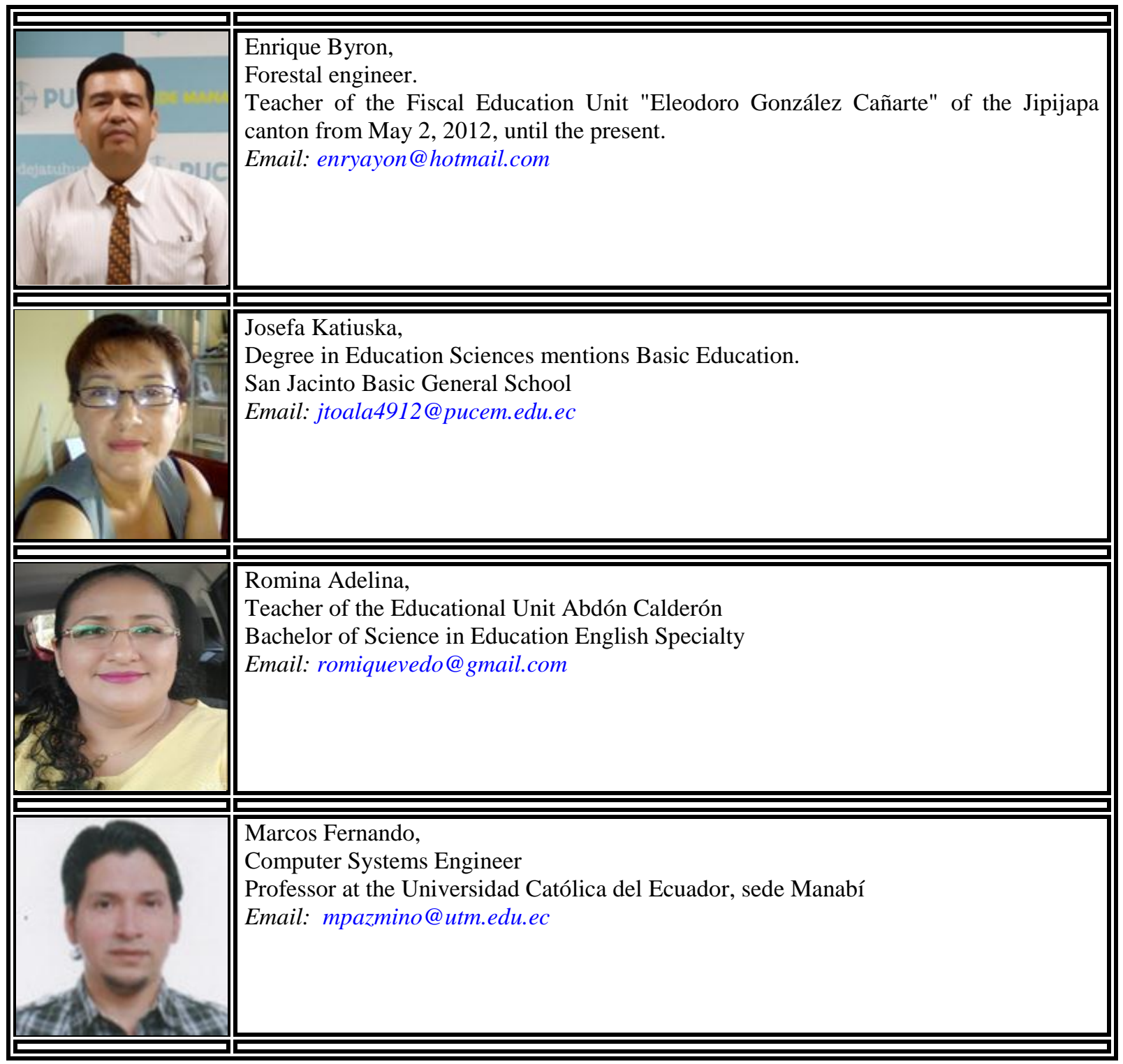

